\title{
MOVILIDAD MÚLTIPLE NACIONAL E INTERNACIONAL DE UNA POBLACIÓN MEXICANO-GUATEMALTECA
}

\section{Mexican-Guatemalans Involvements in National and International Multi-mobility}

\author{
Luis Alfredo Arriola-Vega
}

Resumen: En este artículo se examina la movilidad prolongada de una población mexicana de ascendencia guatemalteca. A tal efecto, se obtuvieron datos a través de métodos etnográficos, principalmente vía testimonios de trayectorias de vida. La perspectiva amplia permite encuadrar la movilidad individual en marcos de análisis más extensos, entre ellos el grupo familiar. La movilidad está influida por ese contexto familiar y por otros factores, como circunstancias coyunturales especificas o el momento en el ciclo de vida del migrante. Migraciones interrumpidas, circulares y de retorno dificultan la comprensión de esas trayectorias porque generalmente son parte de procesos, como flujos mixtos y migraciones continuadas.

Palabras clave: migración, flujos mixtos, migraciones continuadas, migración de retorno.

Abstract: This article scrutinizes the way a Mexican-Guatemalan population has experienced multiple moves over several decades. Longitudinal data was gathered through ethnographic methods to elicit life-long trajectories. The protracted approach makes possible to understand individual mobilities within wider frameworks of analysis, for instance the family group. Because family, particular circumstances, or the life stage of the migrant, affect decisions regarding mobility, in-depth comprehension of personal trajectories gets complicated. At the crux of this complex issue is that interrupted, circular and return migrations, among many types of mobility, become embedded in processes such as contemporary mixed flows and onward-migration.

Keywords: migration, mixed flow, onward-migration, return migration.

Luis Alfredo Arriola Vega, doctor en Antropología por la Universidad de Florida, Estados Unidos. Profesor-investigador en El Colegio de la Frontera Sur, México. Temas de especialización: migraciones y fronteras. Correo electrónico: larriola@ecosur.mx.
Enviado a dictamen: 30 de noviembre de 2015. Aprobación: ll de febrero de 2016. Revisiones: 1. 


\section{Introducción}

$\amalg$ ste trabajo ${ }^{1}$ nace del interés por comprender, a un nivel básico, la experiencia migratoria prolongada de una población inmigrante en México. En el lapso de medio siglo, aproximadamente de 1965 a 2015, los mexicano-guatemaltecos de interés para esta investigación han experimentado varias formas de movilidad que tienen lugar en, desde y hacia el país de referencia primaria, ${ }^{2}$ a saber, de exilio reciente, con trayectorias concurrentes de migración hacia Estados Unidos y de migraciones de retorno hacia Guatemala y retorno "en reversa" a México. Dichas formas de movilidad humana son resultado de procesos históricos contemporáneos más amplios, entre ellos la Guerra Fría y la globalización. Éste no representa un caso excepcional en el mundo, mas sí es único para el sureste mexicano.

El artículo tiene el propósito de indagar sobre la movilidad múltiple que ha caracterizado la experiencia de esta población, ligando trayectorias en el tiempo, y muchas veces vinculando la historia migratoria de abuelos, padres e hijos, a veces nietos, con lugares de origen, destino y retorno. La utilización de un enfoque extendido permite aproximarnos a la naturaleza de la movilidad múltiple vista desde esa lente de una temporalidad diferente. Debido a que los retornos, voluntarios y forzados, forman parte de la movilidad múltiple de los mexicano-guatemaltecos, el tema adquiere particular interés en este trabajo.

\section{Marco conceptual}

Movilidad, trayectoria de vida, temporalidad prolongada, migración-en-marcha. El paradigma de la movilidad se fundamenta en el estudio del movimiento de personas e información en toda su complejidad para conocer "las representaciones, ideologías y significados ligados tanto al movimiento como a la inmovilidad" (Sheller, 2011). Desde esta perspectiva resulta esencial estudiar aspectos "inmovilizadores", tales como demoras, interrupciones y bloqueos a la movilidad, justamente para entender mejor el fenómeno. En el modelo de la movilidad se investiga cualquier forma de movimiento o traslado humanos (Urry, 1999), y todos los tipos de migración son formas de movilidad. Entendida de esta forma, la movilidad incluye por igual a trabajadores pendulares, refugiados, turistas y otros.

Como la movilidad es entendida como algo corporal, nunca virtual (King, 2012), no conviene llevar el paradigma al extremo de la hipermovilidad. Asimismo, se hace difícil concebir que prevalece un entorno de ultra-movilidades ante una realidad en la cual los regímenes para gestionar la migración y los controles sobre ciertas fronteras entre países son cada vez más restrictivos. Para Stephen Castles continúa siendo más pertinente hablar de migración que de movilidad aunque en términos absolutos la cantidad de migrantes ha crecido recientemente en relación con el total de la población mundial, aún es poca la gente que logra migrar, cada vez hay más limitaciones para que ciertos grupos puedan movilizarse y un número considerable de personas no cuenta con los recursos financieros o goza de los derechos políticos para migrar. Este autor agrega que la migración, a diferencia de la movilidad, revela o se acerca más a la realidad de las relaciones de poder incrustadas en la movilización (Castles, 2010: 1567). ${ }^{3}$

El presente trabajo se apega a los enfoques de ciclos y trayectorias de vida (Jasso, 2003; Gardner, 2002), en los cuales interesa una visión de largo aliento en el devenir migratorio del sujeto migrante $y$, hasta donde los datos empíricos lo permiten, de familia inmediata, particularmente de los hijos (King et al., 2006: 245). Aunque la movilidad puede ser motivo para la separación familiar - padres que abandonan a su familia, hijos que no se comunican, etcétera-, en muchos casos ésta también da lugar a relaciones temporales y espaciales entre personas (Findlay et al., 2015: 391). La movilidad puede relacionar a los integrantes de una familia, incluso más allá de las trayectorias individuales divergentes, a los que se van con los que se quedan y a los migrantes con instituciones - verbigracia, los gobiernos que regulan la movilidad - (Findlay et al., 2015: 391), además de vincular los lugares de salida, llegada, tránsito o retorno. Es en ese entramado de vínculos donde se urde la movilidad múltiple, particularmente en relación 
con el grupo familiar y, por ello, aquí interesa trazar historias, si bien parciales, que ejemplifiquen esta polimovilidad.

Y es que sólo hasta tiempos recientes se ha empezado a poner énfasis en la temporalidad prolongada a la hora de teorizar sobre los movimientos migratorios (Bivand y Ezzati, 2015: 1203). Peter Loizos presta especial atención al sentido de esa temporalidad vinculada a migraciones forzadas y al significado que tiene para distintas generaciones porque: "La migración forzada introduce un tipo diferente de disyuntiva en la temporalidad en el sentido de que separa la experiencia en dos períodos: antes y después" (Loizos, 2007: 193, traducción propia). El exilio provoca pérdida de continuidad con el pasado, con la noción de hogar (home), algo que el mito del retorno hace más complicado (Zetter, 1999), especialmente cuanto más tiempo transcurre desde la salida de ese hogar.

Otra idea fundamental en este trabajo consiste en considerar el caso empírico de los mexicanoguatemaltecos como parte de las así llamadas migraciones-en-marcha o continuadas (on-migration o onward migration). Lo anterior significa que un migrante puede embarcarse en un viaje hacia un destino que considera final, pero que posteriormente se vuelve provisional, dejando abierta la posibilidad de re-migrar; o puede ser que la persona se encuentre atrapada-enla-movilidad (Hess, 2012: 435) pero con la intención de continuar migrando. Así, la migración circular, la migración de paso e incluso un retorno pueden estar vinculados a, o ser parte de, migraciones continuadas. Consideremos la experiencia de los originarios de Galicia, España, como caso ilustrativo de retornos en el marco de migraciones en marcha. Los gallegos se han movilizado a México y otros países, y han protagonizado importantes migraciones de retorno, incluso de terceras generaciones (Armas, 2009; Ferrás, 1999). Omata, para citar un caso que semeja al de los mexicano-guatemaltecos, da cuenta de lo que sucedió a exrefugiados liberianos después de que regresaron a su país desde Ghana. Además de que muchos tuvieron que someterse a una repatriación obligada, en algunos casos la familia se dividió al retornar, es decir, una parte regresó a Ghana y otra no; otras personas continuaron movilizándose a terceros países después de haberse repatriado. Otros exrefugiados consideraban el regreso a Liberia como algo temporal y tentativo (Omata, 2013: 1294).

En el esquema de migraciones continuadas, determinados especialistas se inclinan por sugerir que las distinciones entre migraciones voluntarias y forzadas son cada vez más sutiles y que, por tanto, debemos considerar el surgimiento de lo que se ha denominado flujos o migraciones mixtas (ACNUR, 2009), caracterizadas por motivaciones heterogéneas para migrar, así como por la naturaleza variada de las poblaciones en movimiento (Van Hear, 2009: 1535 y 2011: 18-19; Martin, Weerasinghe y Taylor, 2014). Yarris y Castañeda (2015) han abogado por que el sentido convencional de persona desplazada incluya tanto a migrantes como a refugiados. Ellos presentan tres argumentos para problematizar la diferenciación actual de los dos términos: a) que la construcción "discursiva" que habla del desplazamiento es reflejo de sistemas (regimes) de poder y de ciertos intereses que imponen esas dos categorías dicotómicas, b) que no se toma en cuenta la capacidad de gestión autónoma (agency) de los individuos y c) la idea habitual de que los migrantes son quienes van en busca de mejores oportunidades - por su propia voluntad-, mientras que los refugiados son forzados -involuntariamente- a salir de sus lugares para proteger su seguridad. Así, las razones del desplazamiento en el contexto mundial actual suceden en un continuo entre moverse voluntariamente y movilizarse forzosamente (Yarris y Castañeda, 2015: 64). En ese mismo sentido, Zetter afirma que la etiqueta de refugiado y el sistema (regime) que ha surgido en torno a esta categoría deben ser reevaluados a la luz de nuevas migraciones forzadas, del proceso globalizador y de las migraciones mixtas (Zetter, 2007: 174). Para los entonces refugiados guatemaltecos, la experiencia del refugio no constituyó un proceso finito e inmovilizador, es decir, no representó un obstáculo para continuar movilizándose dentro y fuera de México. Incluso el regreso a Guatemala, como se explicará más adelante, dio lugar, a su vez, a otra movilidad posterior. 
Retorno de refugiados. Las razones para el retorno de poblaciones refugiadas, al igual que de otros grupos, suelen ser de índole particular. La edad a la que se vuelve puede ser crucial porque la etapa en el ciclo de vida al momento de la emigración o huida influirá más adelante en el proceso de asentarse o retornar; generalmente las personas de edad avanzada tienen más inclinación que los jóvenes a concretar el retorno porque es mayor su afecto al país de origen. Puede ser que la intención no necesariamente coincida con el resultado esperado, porque lo que originalmente se pensó como un regreso transitorio puede transformarse en algo perdurable (King y Christou, 2011: 453). Desde un punto de vista "estructural", las razones principales de retorno entre los refugiados están determinadas por las condiciones - concretamente las políticas gubernamentales en el país de origen- y los recursos -físicos, institucionales - a los que tiene acceso la persona que retorna (Bhatt y Roberts, 2012: 164).

Para quienes han sido refugiados por mucho tiempo la decisión suele plantear un dilema difícil (Omata, 2013: 1294). Quedarse o partir puede tener muchas aristas porque: "la manera en que los migrantes se relacionan con el país de origen y con el país donde se asientan cambia a lo largo del tiempo, lo cual tiene implicaciones sobre el proceso de asentamiento y el proceso de retorno" (Bivand y Ezzati, 2015: 1202, traducción propia). El hecho de que las intenciones cambien en el transcurso de los años puede hacer ambigua la decisión del retorno. Aunque sea sólo a nivel emocional, pensar en la posibilidad de retornar es crucial para algunos (Bivand y Ezzati, 2015: 1207), algo que resalta más cuando el regreso perdura como un anhelo no materializado. Las motivaciones también pueden no ser tan precisas porque los refugiados - y para el caso otros migrantes- "se embarcan cada vez con más frecuencia en travesías impredecibles y fragmentadas, o se quedan varados, para luego continuar sus periplos migratorios, en una secuencia de movimientos no planificados [...]" (King y Christou, 2011: 460, traducción propia), o sea, de movilidad continuada. Con múltiples y posibles destinos resulta cada vez más limitado apegarse a categorías binarias en términos absolutos —emigración versus inmigración; origen versus destino, etcéteracomo ya lo han señalado otros autores (Collyer y de Hass, 2012; King y Christou, 2011).

El regreso de la segunda y subsiguientes generaciones y clasificación de retornos. Existe un interés creciente por entender este tipo de movilidad porque los casos empíricos abren una gama de posiciones hacia el retorno, es decir, actitudes negativas por un lado, y favorables por el otro. Pero siempre hay mucho más detrás de esa decisión, tal como nos recuerda Naluwembe Binaisa:

Para algunos miembros de la segunda generación el "retorno ancestral" opera como el eje alrededor del cual giran sus vidas, mientras que para otros ya es un anacronismo. Entre los dos extremos de esta dicotomía existe un panorama mucho más complejo donde la capacidad de gestión autónoma, la identidad, la condición migratoria y la dimensión temporal segmentan transversalmente los ámbitos sociales transnacionales (Binaisa, 2011: 521, traducción propia).

En otro caso, relacionado con refugiados chipriotas de origen griego, el retornar conllevaba sentimientos encontrados para miembros de la segunda generación por la complicada integración a una sociedad que "[...] no sólo ha[bía] cambiado durante el período del exilio prolongado, sino que [...era] desconocida y probablemente antipática. Como segunda generación que regresa, serían... refugiados en reversa, una experiencia potencialmente alienante y desintegradora" (Zetter, 1999: 18, traducción propia)

En la literatura especializada se han desarrollado varias tipologías del retorno de migrantes (ver, entre otras, las de Gmelch, 1980 y Cassarino, 2004) e incluso se ha propuesto un modelo para México (Durand, 2004). King y Christou (2011) plantean varias clases con relación al retorno de exiliados y refugiados: primero consideran las visitas cortas, caracterizadas porque involucran viajes de un par de meses principalmente con el objeto de mantener el contacto con familiares; en segundo lugar consideran los viajes que pueden ser repetitivos y llevar a una reubicación futura, pero no 
siempre culminan en un regreso permanente, y un tercer tipo lo constituye la movilidad de retorno de menores de edad, hijos de migrantes, es decir, cuando los padres se llevan a los hijos - la cual no excluye la opción de una re-emigración posterior- . Otra clase más, que coincide con las tipologías clásicas del retorno, es la denominada ancestral o étnica. Ésta hace referencia al regreso de descendientes a la tierra de los antepasados (King y Christou, 2011: 458-459). Los mexicano-guatemaltecos pueden ser clasificados de acuerdo con estos tipos debido a la migración-en-marcha y los múltiples desplazamientos que han emprendido en las últimas décadas, porque una persona quizá fue inicialmente refugiado, luego decidió repatriarse o bien convertirse en migrante económico, y a la postre decidió regresar a México.

Retorno no sustentable, re-emigración y retornos "fallidos". Según Bhupinder Chimni, se ha carecido de una reflexión teórica crítica sobre las condiciones del "retorno sustentable" de los refugiados a sociedades postconflicto, para así recomendar soluciones a diversas inseguridades, sean éstas de orden físico, social, sicológico, legal o material (2002: 168). Agrega Chimni que, de no existir las circunstancias necesarias para garantizar esas diversas dimensiones de seguridad, las personas pueden verse forzadas a refugiarse otra vez (2002: 168). Lo anterior se debe examinar, además, considerando lo siguiente: al cambiar las condiciones en la sociedad de origen, los que regresan pueden ya no sentirse en casa, lo que induce al deseo de re-emigrar entre muchos de ellos (Lietaert, Derluyn y Broekaert, 2014: 145). Además de que los lugares donde vivieron los exrefugiados guatemaltecos experimentaron cambios importantes durante los años que duró su exilio - transformaciones que fueron decisivas para que ocurrieran re-emigraciones-, puede señalarse que difícilmente se atendieron las condiciones mínimas necesarias para un reasentamiento digno en Guatemala. ${ }^{4}$

El retorno puede estar marcado por ambivalencia y ambigüedad — identitaria, de pertenencia-, por la adaptación o integración fallida a la sociedad de acogida o por la posible re-emigración, entre otras posibilidades (King y Christou, 2010), y por ello deviene, en muchos casos, en una quimera que decepciona e induce contra-retornos (King y Chirstou, 2011: 454). Tal como dice Kristi Stølen (2009), en el mito del retorno se da por hecho la existencia de un vínculo natural entre las personas que se refugiaron y los lugares de donde salieron, pero Lietaert y colaboradores (2014: 145) señalan, atinadamente, que la vida "nueva" en un contexto "viejo" suele ser difícil. Más adelante se evidenciará que eso fue lo que sucedió a muchos de los entonces refugiados guatemaltecos.

Finalmente, no podemos pasar por alto una forma de movilidad contemporánea experimentada por la población objeto de estudio: la deportación desde Estados Unidos de mexicano-guatemaltecos que viajaron sin autorización a ese país. Esta situación no es privativa de Utepe (pseudónimo de la localidad de estudio), sino que puede generalizarse a todo México. Dicha problemática se hizo más crítica debido a la implementación de políticas restrictivas a partir de la aprobación de la ley conocida como IIRCA (Illegal Immigration Reform and Immigrant Responsibility Act) de 1996, el reforzamiento progresivo de las fronteras, el endurecimiento de acciones en la lucha antiterrorista posterior al $\mathrm{ll}$ de septiembre de 2001 y las deportaciones masivas en tiempo más reciente. Este panorama ya es objeto de reflexión por parte de algunos estudiosos. Por ejemplo, Nicholas de Genova (2010) ha formulado que en países como Estados Unidos ha surgido todo un "sistema" (regime) de deportación vinculado a la restricción del movimiento de personas por parte del Estado nacional basándose en el poder "inherente" que le otorga la soberanía nacional. Esta práctica deviene de la expansión de políticas con sello securitario (securitization), fronteras militarizadas y otras restricciones que influyen en todo tipo de movilidad, lo cual afecta mayormente a aquellas personas que llevan una "existencia mínima" (barelife) debido a su condición migratoria irregular (De Genova, 2010: 34, 37 y ss.). Otra perspectiva afín es la que propone la criminalización de los migrantes como fundamento para su expulsión, producto de políticas de control policíaco inmersas en un "modelo de detención migratoria" (Wilson, 2015). La expulsión de mexicanos, incluyendo originarios del 
sureste mexicano, ${ }^{5}$ ha sido un fenómeno de grandes proporciones en Estados Unidos ${ }^{6}$ (Castañeda, 2012; Debry, 2012; Wheatley, 2011).

\section{Contexto}

Utepe es una comunidad que se encuentra a una distancia aproximada de ochenta kilómetros al sureste de la ciudad de Campeche. Sus habitantes llegaron en calidad de refugiados a México entre 1980 y 1983 debido al conflicto armado que azotó Guatemala. En 1983, los entonces refugiados fueron reubicados desde Chiapas, en un traslado que incluyó períodos en tránsito, es decir, tuvieron que residir provisionalmente en algunos lugares - por ejemplo, Chiná y Hecelchakán, del municipio de Campeche-, antes de llegar a otro destino, Caracoles (pseudónimo). Debido a la falta de lotes para vivir adecuadamente y de tierra disponible para labores agrícolas, una parte de los residentes de Caracoles aceptó reubicarse en Utepe, aproximadamente entre 1989 y 1991. Así, de 1983 a 1990 los entonces refugiados experimentaron varios reasentamientos, a la vez que ya algunos contemplaban el retorno a Guatemala. En 2013 Utepe contaba con una población aproximada de 3400 personas según datos recabados por la agencia municipal local. ${ }^{7}$ Sus habitantes tenían diversos orígenes, predominando las comunidades etnolingüísticas mam, q’anjobal, keqchí, ixil y chuj. Una parte de los entonces refugiados decidieron establecerse en México y con ello integrarse al país. En ese punto resulta útil precisar la forma en que se denomina a la población objeto de interés. Aquí se emplea "generación" en el sentido "general" de ascendencia por parentesco, sin perder de vista las dificultades que esto conlleva, como se explica en breve. La primera generación incluye a quienes nacieron en Guatemala y optaron por hacerse ciudadanos. Se identifica a los individuos que arribaron a México siendo niños menores de cinco años, quienes han vivido prácticamente toda su vida en el país, como la generación 1.5. La segunda generación está compuesta por todos los nacidos en
México que son hijos de los anteriores estratos. Pero las diferencias entre los estratos generacionales 1.5 y 2 pueden resultar muy tenues cuando se toman en cuenta consideraciones adicionales a la estirpe. Loizos (2007) advierte que, además de tener cuatro usos analíticos (con base en el trabajo de Kertzer, 1983), resulta complicado emplear "generación" con una población de desplazados, o refugiados, cuando hablamos de un grupo que incluye gente de todas las edades posibles. Si tomamos un grupo de refugiados cuyas edades van de los 0 a los 30 años, como un ejemplo ficticio, hay un período de tres décadas dentro del cual las metas de cada persona, su capacidad laboral y sus relaciones de dependencia — su situación en el ciclo de vidavarían considerablemente. Dice Loizos:

Todos fueron desplazados al mismo tiempo; nacieron en el mismo período; sus edades oscilan en ese lapso de 30 años [...] Pero las generaciones "etic" fabricadas por los etnógrafos que estudian las vidas de refugiados y los estudiosos de la migración constituyen una tentativa para imponer otro orden conceptual, más formal, dentro de un torrente de gente que se mueve en el mundo [...] (Loizos, 2007: 205, traducción propia).

Dos casos en la comunidad que nos ocupa evidencian las dificultades inherentes al uso del término generación. Por ejemplo, Timotea (entrevista 7) nació, literalmente, en la delimitación internacional que comparten México y Guatemala, si bien sus padres habitaban en el Ixcán guatemalteco. Antes de salir al refugio, su familia iba y venía entre uno y otro país. Ella creció en Chiapas como refugiada no reconocida y más tarde formó parte del grupo que retornó a Guatemala para, a la postre, regresar de nuevo a México. Algo similar sucedió con Darío (entrevista 18), quien nació en Chiapas y cuya vida transcurrió vinculada a diversas clases de movilidad, entre ellas la reubicación, el retorno y la migración a Estados Unidos. Ambos pertenecen, desde un punto de vista estrictamente cronológico, 
a la generación 2, pero la experiencia particular del refugio y las trayectorias de sus vidas en la movilidad múltiple hacen que compartan características con la generación 1.5 , lo cual dificulta ubicarlos propiamente en un solo estrato.

\section{Aspectos de método}

La obtención de datos se hizo a través de observación participante y de entrevistas semiestructuradas durante varios meses de 2014 y 2015. Para la selección de colaboradores recurrí al método conocido como bola de nieve: un primer informante me llevó a otro, éste a su vez a un tercero, y así sucesivamente. Todos los informantes habían alcanzado la mayoría de edad. Participaron quince hombres y ocho mujeres; de ellos dieciséis eran personas indígenas y siete, ladinas. ${ }^{9}$ En las entrevistas se indagó sobre la historia migratoria del informante a lo largo de su vida y sobre las movilizaciones de la familia inmediata — padres, hermanos, hijos—, si bien no se profundizó en sus trayectorias. La entrevista se diseñó y aplicó generalmente en forma individual, pero en los hechos hubo excepciones: aconteció que se realizaron entrevistas a tres parejas de cónyuges como una sola (entrevistas $1,11,15$ ), y dos de padre e hijo (entrevistas 4 y 9, y 12). La entrevista individual permitió establecer con claridad el inicio y final de cada tipo de movilidad, pero estudiar trayectorias personales inconexas ayuda poco a comprender las lógicas de la multi-movilidad en un marco de referencia más amplio, como puede ser el grupo familiar. Así, las diadas de entrevistas enriquecieron el estudio de la movilidad múltiple a la vez que complicaron lograr un amarre integral de las historias migratorias en su conjunto. Una arista de esa complejidad es que pueden surgir aparentes contradicciones y movimientos migratorios divergentes entre distintos entrevistados, porque los periplos personales no siempre están determinados por decisiones o circunstancias aisladas o subjetivas, como hijos que deben ir con los padres, esposas que siguen a los maridos o retornos involuntarios. Este punto se hará claramente evidente en los casos ilustrativos presentados en la penúltima sección.

\section{Caracterización de la movilidad de los mexicano- guatemaltecos}

Se han delimitado, de manera arbitraria, tres períodos de referencia de movilidad entre los entrevistados de Utepe. El primero corresponde al intervalo 1965-1980, que corresponde a los acontecimientos ocurridos en Guatemala antes de la huida a México. Un alto porcentaje de los que llegaron en calidad de refugiados no lo hicieron desde los territorios en los cuales nacieron o crecieron, sino más bien desde zonas a las cuales habían llegado a colonizar. Así, miembros de la generación 1.5 nacieron en estos territorios de fronterafrente, mientras que sus progenitores - primera generación - nacieron en otro lugar. La fase de refugio inició hacia 1980 y terminó hacia 1993. Si bien ésta sirve como la etapa toral para articular procesos de movilidad pre y postrefugio, se verá que dicho eje resulta un tanto "descentrado" dependiendo de quién sea el sujeto estudiado y del momento del cual se esté hablando. El tercer período abarcó de 1990 hasta el presente, y es el más dinámico porque acontecen varios tipos de migración, como se explicará en breve.

\section{Procesos de movilidad}

Se desarrollaron ocho procesos con rasgos distintivos cada uno. Al final de la sección se presenta un cuadro sinóptico para que el lector pueda cotejar el constructo interpretativo - procesos - versus la evidencia empírica —datos obtenidos en campo-. El penúltimo apartado incluye casos representativos para ilustrar con más detalle la movilidad múltiple.

1. Colonización. Hace referencia al arribo de la primera generación y sus descendientes para colonizar el norte de Guatemala, en El Petén y en Ixcán. ${ }^{10} \mathrm{La}$ historia de comunidades pioneras que llegaron a fundar cooperativas en El Petén occidental, a la vera del río Usumacinta, limítrofe con México, se remonta a la mitad de la década de 1960. Allí habitó población ladina e indígena (Artimus, 1974). El Ixcán fue un frente para la expansión de la frontera agrícola, en un proyecto impulsado por la Iglesia católica (Melville y 
Melville, 1982; Vallejo, 2000). Esos colonizadores, por lo general indígenas, fueron llevados principalmente desde el Altiplano guatemalteco hacia tierras bajas. El conflicto armado que vivió Guatemala (CEH, 1999; ODHAG, 1998) involucró al ejército gubernamental y a organizaciones guerrilleras y azotó con particular fuerza al Petén occidental y a todo Ixcán por la presencia directa de insurgentes; la política de tierra arrasada utilizada por las fuerzas armadas de Guatemala para eliminar a los combatientes de la guerrilla y a sus seguidores desarraigó a miles de no combatientes civiles, mayormente entre 1980 y 1985. Con excepción de Dominga (entrevista l), el resto de informantes fueron colonos en Ixcán o El Petén, o hijos de progenitores colonizadores.

2. Desplazamiento forzoso. Un proceso vinculado a la dinámica de la guerra que se vivió tanto en El Petén como en Ixcán fue el desplazamiento forzado dentro de Guatemala que experimentaron muchos de los que, a la postre, saldrían como refugiados a México (AVANCSO, 1990). Este desplazamiento pudo durar desde varios meses, hasta dos años. Los futuros refugiados tuvieron que vivir en "la montaña", es decir, se vieron forzados a abandonar sus viviendas, morar a campo abierto y movilizarse constantemente ante la persecución de la que fueron objeto. Por lo menos quince de las personas entrevistadas experimentaron el desplazamiento interno.

3. Elrefugio. Sobre el proceso de refugio guatemalteco en México se ha escrito abundantemente (Memoria..., 1999; Kauffer, 2000; Ortiz, 2011) y aquí interesa, ante todo, señalar aspectos útiles para tender puentes entre lo acontecido antes y después del exilio. De quienes huyeron a México debido al conflicto armado, hacia 1989 unas 45000 personas obtuvieron el reconocimiento como refugiados oficiales (Pérez, 1999). ${ }^{11}$ En 1984 el Gobierno mexicano decidió trasladar a Campeche y Quintana Roo a los refugiados guatemaltecos que aceptaron la reubicación desde los campamentos ubicados en Chiapas, pero hubo quienes se opusieron; las familias de Pedro (entrevista l) y Timotea estuvieron entre los que se negaron. ${ }^{12}$ Según cifras oficiales, fueron trasladadas 12500 personas a Campeche y
6000 a Quintana Roo, si bien después llegaron más (Castillo, 1999: 37). Este reasentamiento significó comenzar de nuevo para los entonces refugiados. A partir de 1996 se transitó del refugio a un proceso de integración para aquellas personas que decidieron no retornar a Guatemala, para lo cual el Gobierno extendió inicialmente documentos migratorios varios $y$, por último, otorgó la carta de naturalización a quienes optaron por hacerse ciudadanos mexicanos.

4. Migración interna. Ante la necesidad de obtener ingresos para sostener a sus familias, los hombres, y luego las mujeres, buscaron empleo en la región. Refieren los entrevistados que al inicio las autoridades les permitieron trabajar en determinados oficios, entre ellos el corte de la caña de azúcar en las empresas agroindustriales próximas a las localidades de los refugiados - los actuales ingenios La Joya en Champotón, Campeche, y San Rafael de Pucté, en Othón P. Blanco, Quintana Roo-. Eran movilizaciones de corta duración, de semanas, pero, debido a que la remuneración que se obtenía en esos empleos era más bien modesta, los entonces refugiados decidieron aventurarse, sin autorización, a conseguir otros empleos. En el grupo de estudio, al menos ocho hombres indicaron que acudieron a trabajar a la industria de la construcción en Cancún y la Riviera Maya; una mujer lo hizo en el servicio doméstico. ${ }^{13}$ Por ejemplo, Lucas (entrevista 15) refirió haber ido a laborar a La Joya en cuatro ocasiones, cuatro semanas en cada temporada, y posteriormente se dirigió a Cancún, donde trabajó de albañil en ocho ocasiones por períodos de un mes.

5. Migración internacional. Una vez logrado cierto nivel de estabilidad y pasada la etapa de emergencia, ${ }^{14}$ los entonces refugiados guatemaltecos y sus descendientes empezaron a dirigirse a Estados Unidos, ${ }^{15}$ a lo cual contribuyeron varios procesos. Primero, para quienes se hicieron ciudadanos su nuevo estatus migratorio les facilitó la libre movilización por todo el territorio mexicano, lo que contribuyó a que se extendiera la migración interna, por ejemplo, a destinos de la frontera norte de México. De ahí, "dar el brinco" a Estados Unidos fue sólo cuestión de tiempo. En segundo lugar, hacia 1994 la población de los entonces refugiados 
estaba compuesta casi en partes iguales por nacidos en México y originarios de Guatemala (Sáenz, 1999: 129). Los hijos de los refugiados fueron quienes emprendieron, en mayor número que sus padres, el viaje a Estados Unidos. Un tercer factor lo constituye el inicio de la emigración desde las localidades de origen del Altiplano guatemalteco, en la década de 1970, hacia ese país. A este respecto, Camus (2008), por ejemplo, examinó en su trabajo el caso de un municipio q'anjobal de Huehuetenango. La guerra interna agudizó la migración hacia Estados Unidos desde regiones indígenas, lo que dio lugar al surgimiento de redes sociales que progresivamente alimentaron la continuidad en el flujo; según Susanne Jonas y Néstor Rodríguez, esto corresponde a la primera fase, 1977-1985, en la historia de la migración guatemalteca a Estados Unidos (Jonas y Rodríguez, 2015: 34-41). ${ }^{16}$ La fecha más temprana detectada de alguien que se dirigió a Estados Unidos fue 1997: Mateo (entrevista 9), quien llegó a México siendo niño y emigró al extranjero a la edad de 20 años. Además de Pedro, Mateo y Darío, también fue a ese país Anastasio (entrevista 12). Otros parientes —cónyuge, hijos, hermanos, etcétera- relacionados con diez del resto de entrevistados también emprendieron este tipo de movilidad.

6. Repatriación y retorno. Una parte de los entonces refugiados regresaron a su patria en dos modalidades. La primera de ellas involucró la repatriación por decisión individual o familiar. Las repatriaciones iniciales - 1984 - fueron motivadas por la reubicación hacia Campeche y Quintana Roo (AVANCSO, 1992: 49). Desde 1986 las repatriaciones se realizaron por un acuerdo conjunto entre el Gobierno de México, el de Guatemala y el ACNUR, a partir del cual en el período comprendido entre 1986 y 1989 se trasladaron unas cuatro mil personas a Guatemala (González, 1999: 74). Tras diversas negociaciones entre representantes de los refugiados y las autoridades de Guatemala, en octubre de 1992 se firmó un acuerdo por medio del cual se planificó una modalidad de retornos "organizados y colectivos" a ese país y se estableció que los refugiados retornarían en grupos, podrían negociar dónde reubicarse según diversas circunstancias, se les dotaría de tierras en caso de carecer de ellas y se les brindaría servicios básicos e infraestructura. Para 1999 más del 75\% — cerca de 42000 personas - de la población que ingresó a México en calidad de refugiada había regresado a Guatemala (García, 1999: 147), donde una investigadora indicó que se fundaron más de ochenta comunidades de retornados (Stewart, 2012: 408). Así, el retorno organizado aconteció de manera casi simultánea a las nacientes migraciones internas e internacionales, y también dio origen muy rápidamente a un retorno "en reversa". Debido a que los exrefugiados o sus hijos decidieron continuar migrando, resulta útil tomar en cuenta el comentario siguiente: "La integración, la repatriación o la reubicación no deben asumirse como eventos finitos. Por el contrario, una subsecuente migración (secondary migration) debe ser reconocida como parte de un proceso que puede involucrar una combinación de estos acontecimientos" (Jeffery y Murison, 201l: 137, traducción propia). En el grupo de colaboradores sólo se detectó a una mujer que se repatrió a Guatemala (Soledad, entrevista 11), quien lo hizo en un momento relativamente tardío -1998 - y con apoyo limitado, aunque regresó a México al poco tiempo. En la selección de informantes se buscó intencionalmente a personas que habían participado en el retorno colectivo a Guatemala y que, igualmente, emprendieron el contra-retorno. Los colaboradores de las entrevistas 1 (ambos cónyuges), 10 (Everardo), 12 (Ramón), 13 (Carlota), 15 (ambos cónyuges) y 17 (Fermín), además de las de Darío y Maricela, representan ambos tipos de movilidad.

7. Regreso posterior a México desde Guatemala. En un lapso muy breve, incluso de meses, algunas personas que fueron refugiadas y que habían retornado a Guatemala emprendieron el viaje de regreso a la tierra que les dio asilo, o los vio nacer en el caso de los hijos de refugiados. Las razones de este contra-retorno incluyeron decepción porque no se cumplieron sus expectativas de lo prometido - entre otros aspectos, falta de acceso a servicios básicos e infraestructura- ${ }^{17}$ incapacidad para adaptarse a las condiciones locales y al estilo de vida - aislamiento en zonas rurales recónditas, tierras improductivas o conflictos comunitarios internos-, 
o la inseguridad pública en el lugar de destino - la violencia delincuencial que se desató en el período postconflicto en Guatemala-. Otro punto a considerar es que el lugar al que regresaron ya no era el mismo, y los exrefugiados tampoco eran las mismas personas que se fueron. Stølen hace una aguda reflexión al respecto en la introducción a un texto sobre La Quetzal, en El Petén, comunidad a la cual retornó Fermín:

La repatriación se concibe como la solución lógica y natural al desplazamiento de los refugiados, al restablecimiento de un orden que vincula a la gente, la cultura y el lugar [...] Estas ideas sobre la repatriación no sólo conllevan retornar físicamente a la patria, sino un regreso a sus ya conocidas identidad, cultura y forma de vida [...] El caso de los retornados guatemaltecos [...], sin embargo, demuestra que tales ideas tienen poco que ver con lo que el retorno significa para ellos. No sólo han cambiado sus condiciones de vida y la percepción que tienen de ellos mismos y del "mundo", sino también de las comunidades y de la gente que se quedó (Stølen, 2009: 80, traducción propia).

En síntesis, para muchos de los grupos de retornados —no todos- ${ }^{18}$ las condiciones socioeconómicas en las que se reinsertaron no fueron las más favorables y por ese motivo algunos decidieron volver a México. Las diferencias generacionales también influyeron decisivamente en el contra-retorno. Muchos hijos de los exrefugiados se opusieron a la idea de ir a Guatemala debido, es posible, a que se sintieran alienados en la tierra de sus antecesores. Esto fue lo que detectó Stewart en 1998 en una comunidad de retornados en Ixcán, en la cual los jóvenes manifestaron estar aburridos y aislados. Rosseau y colegas (2005) descubrieron algo similar, en 1999, entre personas jóvenes de la comunidad llamada Victoria 20 de Enero, comunidad donde se sentían decepcionados por el "abandono" de organizaciones externas que los habían apoyado inicialmente, por las divisiones internas y porque extrañaban la vida en México (Rosseau et al., 2005: 7). En Nueva
Generación Maya, una comunidad de retornados en el norte de Huehuetenango, Camus encontró que los jóvenes estaban "desesperados" por "la pérdida de bienestar y empleo" al retornar (2008: 218). ${ }^{19}$ Estos investigadores reportaban que ya había jóvenes que regresaron a México y que otros iban y venían entre Guatemala y ese país, es decir, que aun cuando el proceso de retornos colectivos no había finalizado, ya operaba el retorno en reversa porque, por ejemplo, algunos nacidos en México optaron por regresar, especialmente al cumplir la mayoría de edad, y otros por la presencia de sus descendientes en la entidad, no porque les fuese mal en Guatemala (entrevista 15). Casi todos los contra-retornados pudieron asentarse nuevamente en Utepe o sus cercanías porque tenían parientes que no regresaron a Guatemala, algo similar a lo señalado para una comunidad en Chiapas (Lerma, en prensa). También hubo situaciones en las cuales el contra-retorno a México fue más complicado, como se detalla en uno de los casos ilustrativos (entrevista 13).

8. Retornos forzados y retornos voluntarios desde Estados Unidos. Si bien no existen cifras exactas sobre los migrantes que han viajado a Estados Unidos desde Utepe, su número es considerable; en nuestro estudio, en catorce entrevistas se detectó que los propios informantes o uno de sus parientes lo había hecho. ${ }^{20}$ En el grupo de informantes, dos hombres, Pedro y Mateo, habían sido expulsados; uno de ellos lo expresó abiertamente, el otro no. En el grupo de entrevistados también se detectaron casos de migrantes, o familiares, que regresaron voluntariamente después de haber emigrado por un tiempo a Estados Unidos. ${ }^{21}$ Los dos retornados voluntarios (Anastasio y Darío) compartían rasgos: ambos habían ido a Estados Unidos en dos ocasiones y sus períodos de estancia allá habían sido relativamente cortos, entre 18 y 24 meses en cada viaje; ninguno de los dos descartó la posibilidad de volver a migrar, y las familias de ambos habían sido parte del proceso de retorno colectivo, así como del contra-retorno. En el primer caso el interpelado no fue a Guatemala, pero sus padres y varios hermanos sí, mientras que en el segundo toda la familia retornó y volvió posteriormente a México. 


\section{Cuatro casos ilustrativos de movilidad múltiple}

\section{Entrevista l. Pedro y Dominga}

Al momento de la entrevista Pedro tenía 53 años y Dominga 49. Él había nacido en el departamento de Huehuetenango, donde vivió hasta los cuatro años porque después la familia se trasladó al norte del Ixcán, en Quiché, a un lugar cercano a la frontera con México. Pedro, de la comunidad etnolingüística mam, se inició como migrante laboral a los 14 años, edad a la que viajó a Benemérito de las Américas, en Chiapas. Cuando la situación de violencia se intensificó en Guatemala, hacia 1980, decidió buscar refugio. Dominga era originaria de Chajul, en el departamento de El Quiché, en territorio de la comunidad etnolingüística ixil, donde creció y vivió hasta 1980, cuando ella y tres primas fueron enviadas a otro municipio a raíz del asesinato de familiares posiblemente a manos del ejército guatemalteco. En ese lugar ella entró en contacto con los guerrilleros que combatían al gobierno y fue invitada a unirse al grupo, aunque rehusó. Salió a México después de haber vivido en "la montaña" por algún tiempo. En 1983 la pareja se conoció en un campamento de refugiados en Chiapas, donde nacieron sus hijos. Pedro fue a trabajar a Cancún durante seis meses en algún momento entre 1983 y 1985 y después consiguió trabajo con una organización que apoyaba a los refugiados. Esta pareja formó parte de aquellos que decidieron no trasladarse a Campeche o Quintana Roo, por lo que permanecieron en Chiapas hasta el momento del retorno organizado. La familia de Pedro y Dominga retorno a la comunidad Victoria 20 de Enero, en Ixcán. Ella no quería regresar pero, debido a que no tenía familia inmediata en México, siguió al marido. La vida en Victoria fue muy dura porque al inicio debieron soportar el asedio del ejército guatemalteco, además de que sufrieron por muchas carencias y problemas, como que los niños se enfermaban debido al hacinamiento en el que vivían. Posteriormente, el grupo familiar se reubicó nuevamente en una finca en el departamento de Alta Verapaz, donde los hijos continuaron estudiando y, hacia el año 2000, el mayor de ellos anunció a sus progenitores que tenía intención de volver a México, decisión que se vio influenciada por lo que sus hijos escuchaban de un familiar que se quedó en Campeche y los visitaba. Esta persona hablaba de las ventajas de vivir en México: contaban con apoyos, niños y jóvenes podían optar a becas y había trabajo en el campo. Al cumplir los 18 años, el hijo mayor dijo que iría a trabajar a Cancún - lo cual no sucedió - debido a la imposibilidad de continuar estudios universitarios en Guatemala. Poco antes, y para seguir manteniendo los estudios de los otros hijos, Pedro decidió ir a Estados Unidos, donde llegó en 2001. Su primer trabajo consistió en realizar labores agrícolas en Georgia y posteriormente consiguió empleo en el ramo de la construcción y viajó a otros estados, entre ellos Florida, Nueva York y Pensilvania. En 2011 fue deportado pero ya no volvió a Guatemala, sino que se unió a la familia en Campeche porque María y sus hijos habían emprendido el contra-retorno a Utepe en febrero de 2004, donde residían en la casa del familiar que antes les visitaba en Alta Verapaz.

\section{Entrevista 12. Ramón y Anastasio}

La entrevista incluyó a dos ladinos, Ramón (padre) y Anastasio (hijo). Ramón nació en 1920 en el departamento de San Marcos y en su juventud trabajó como jornalero en las fincas de café. A los 25 años se casó con su primera cónyuge, que murió poco después, por lo que se unió con otra mujer con quien engendró siete descendientes. Hacia 1969 Ramón se integró a un proyecto de colonización impulsado por el Gobierno guatemalteco, la cooperativa El Arbolito, en el municipio de La Libertad, El Petén. Según el informante, allí había presencia de la guerrilla, motivo por el cual fueron objeto de persecución años después. Antes de huir a México, la familia de Ramón y otras más, unas 150, estuvieron "en la montaña" y en 1980 se dirigieron a Benemérito de las Américas, en Chiapas, según el interlocutor por instrucciones de los insurgentes. Allí residieron durante tres años antes de ser trasladados a Campeche. Posteriormente Ramón decidió retornar a Guatemala con cuatro de sus siete hijos porque guardaba la esperanza de dejarles en herencia sus 
tierras, aunque la esposa no quería ir porque ansiaba volver al Arbolito, lo cual no era posible. Mirte (pseudónimo) fue el lugar de destino, en el municipio de La Libertad. A decir de Ramón, la tierra no era buena, el agua escasa y la organización complicada, motivos por los cuales el primer hijo que regresó a México sólo estuvo seis meses en Guatemala. El resto de la familia vivió tres años en Mirte. Ante la insistencia de los hijos que salieron de Campeche, en junio de 2003 Ramón -el único que deseaba quedarse - y el resto emprendieron la travesía de regreso a Utepe. Quilo, el menor de los descendientes de Ramón que retornó, aprendió enderezado y pintura de vehículos en la ciudad de Guatemala — aproximadamente entre 2000 y 2003; es decir que Quilo nunca residió en Mirte- con un hijo de la primera conviviente de Ramón. Después del contra-retorno a México sólo vivió un año en Utepe antes de dirigirse a Estados Unidos. Desde 2005 no había regresado a Campeche.

Anastasio, quien nació en 1980 en El Arbotilo, fue uno de los hijos que se negó a ir a Guatemala. Tenía 3 años cuando su familia se trasladó a Campeche y ahí cursó parte de la escuela primaria, pero a los 13 dejó los estudios para ir a Cancún en busca de empleo. En esa primera ocasión estuvo ocho meses trabajando en el chapeo de solares, y después hizo tres viajes más, dos de ellos cuando ya había formado su propia familia. A partir de su experiencia laboral en Cancún aprendió varios oficios - albañilería, carpintería y manejo de maquinaria agrícola- A la edad de 16 años se unió a su cónyuge y compró un solar a una persona que retornó a Guatemala. En 1998 Anastasio decidió probar suerte en Estados Unidos junto con otro conocido. Llegó a California, donde inicialmente trabajó en jardinería, y en diciembre de 2001 regresó a México, donde sólo se quedó un año porque decidió regresar por segunda vez a Estados Unidos para permanecer ahí durante dieciocho meses.

\section{Entrevista 13. Carlota}

De 45 años de edad durante la entrevista, Carlota había nacido en Huehuetenango y siendo bebé su familia se trasladó a Ixcán. Vivió en carne propia la violencia de la guerra porque en 1981 su madre fue asesinada frente a todos los hijos. Un año más tarde la familia de Carlota se desplazó internamente, hasta que salió hacia México y se ubicó en un campamento llamado Chajul, en Chiapas, para posteriormente reasentarse en Quintana Roo, donde experimentó otra reubicación. En 1989 inició vida conyugal con su actual pareja, también de ascendencia mam, quien decidió que la familia debía retornar a Guatemala, lo que finalmente sucedió. Para entonces ya tenían tres hijos, y otros cuatro nacerían en el lugar al que llegaron en el municipio de Fray Bartolomé de las Casas, en Alta Verapaz. Los tres hijos mexicanos de Carlota regresaron a Utepe cuando alcanzaron la mayoría de edad. El mayor de ellos tramitó su credencial de elector y en cuanto la tuvo se dirigió a Cancún, donde había ido ya varias veces. El segundo hijo fue una sola vez a Cancún y después llegó a Utepe a residir con una cuñada de la informante. Después arribó la tercera hija, quien en 2014 trabajaba en la ciudad de Campeche. Hace algunos años los tres hermanos decidieron pedir un solar a las autoridades en un barrio anexo a Utepe, donde se ubican muchos contra-retornados. Lo peculiar de este caso es que la entrevistada había realizado tres viajes desde Guatemala, entre 2013 y 2015, para ver a sus hijos, con estancias de varios meses durante cada viaje, visitas a las que había llevado consigo a sus otros cuatro hijos, por lo que ella encarnaba un patrón de migración circular. Desde la etapa del refugio, su marido fue a trabajar a Cancún por temporadas. Al momento de la entrevista él estaba en ese destino y a veces visitaba Campeche. También había realizado un viaje desde Guatemala a Estados Unidos entre 2009 y 2010, en una estancia de un año y medio.

\section{Entrevista 15. Jacinta y Lucas}

Éste es el testimonio de una pareja de adultos mayores, ella de 66 y el de 57. Jacinta provenía de una familia de trabajadores colonos en una finca de café de San Juan Cotzal, municipio ubicado en la zona ixil de Guatemala, y aprendió el idioma ixil aunque su familia tenía raíces en la comunidad etnolingüística k’iché. Por su parte, 
Lucas también era de origen k'iché pero nació en Chajul, en donde su padre se dedicaba a la elaboración de cal; de niño fue a trabajar a fincas de café y algodón en el sur de Guatemala. Hacia 1974 Lucas y Jacinta iniciaron vida marital y al siguiente año, después del nacimiento de su primera hija, la pareja se trasladó a San Juan Ixcán. Antes de su salida a México en 1982, la familia estuvo desplazada internamente por instrucciones de la guerrilla, por lo que estuvieron dos años movilizándose constantemente "en la montaña". Al llegar a Chiapas estuvieron asentados en un campamento llamado Mollejón, hasta que poco después, en 1984, la familia fue reubicada en Caracoles con una estadía previa, de semanas, en Hecelchakán. En 1990 el grupo familiar se trasladó a Utepe pero no permaneció mucho tiempo allí debido a que se unió al grupo que retornó a Victoria 20 de Enero. A diferencia de otras mujeres, Jacinta sí se inclinaba por regresar a Guatemala. Los hijos de la pareja habían nacido en distintos lugares: Cotzal, Ixcán, Caracoles y Utepe y, con excepción del menor, todos se resistieron a la idea de morar en Guatemala. El mayor de ellos le dijo un día a Lucas: "Usted ya se acostumbró a jalar la mochila de aquí para allá. Yo ya me cansé." La hija mayor, que ya había formado su propia familia al momento del retorno, regresó a México en menos de tres meses, mientras que Jacinta y Lucas regresaron en 2002 por insistencia de los hijos. Con el tiempo, dos de sus descendientes decidieron irse a Estados Unidos; uno de ellos permaneció algunos años en ese país y regresó a Campeche, mientras que el otro llevaba nueve años al momento de hacer la entrevista -2005-2014-. El hijo menor, de 23 años, que se encontraba presente durante la segunda sesión de la entrevista, era quien más extrañaba Guatemala porque la asociaba con vivencias de su niñez que formaban parte de su identidad, según afirmó. De hecho, había regresado de una visita a El Petén pocos días antes de sostener la entrevista con sus padres.

\section{Reflexiones finales}

Este estudio hizo posible examinar desde una mirada de largo alcance a personas que han emprendido diversas formas de movilidad que comprenden y se extienden, temporal y vivencialmente, más allá de su etapa de refugio. La experiencia en el terreno de estudio obligó a un cambio en el enfoque inicial, centrado en casos individuales, hacia otro que incluyó casos que integraban a parientes de algunos informantes. Dicho reajuste metodológico implicó un reto: si la unidad de estudio es el individuo, podemos construir, hasta cierto punto, trayectorias cerradas; al incluir al grupo familiar cercano se hace más complicado hilvanar toda la secuencia de los periplos de sus integrantes ya que la movilidad cambia, y se hace compleja, a lo largo del tiempo. Seguir la pista a las historias migratorias de cada familia significa integrar trayectorias para las cuales podemos determinar uno o varios puntos cualesquiera de inicio pero, a la vez, dejar abiertas travesías parciales, circulares o de retorno, con las dificultades que ello conlleva. El esquema de movilidad múltiple puede resultar útil para emprender un primer nivel de análisis de procesos sociales dinámicos, pero ciertamente requiere de elementos adicionales para proporcionar una lectura más acuciosa porque las clases de movilidad se traslapan o divergen entre sí. Consideremos lo siguiente: aunque se ha analizado a los exrefugiados guatemaltecos desde la categoría jurídica del asilo, no se ha estudiado la relación de ese estatus con su condición como migrantes económicos. Por ello quizás sea más preciso considerarlos parte de migraciones o flujos mixtos, porque el hecho de que en un momento específico los entonces refugiados salieran a trabajar para sobrevivir los hacía simultáneamente migrantes laborales y refugiados. $\mathrm{O}$ pensemos en el caso, hipotético, de una persona que se dirigió a Estados Unidos pero fue deportada; si ese mismo individuo tiene intención de re-emigrar puede percibir su estancia en México como algo pasajero: ise le debe considerar migrante de retorno o circular? Este tipo de complejidades está estrechamente ligado con el problema teórico de establecer conceptos flexibles pero abarcadores porque la heterogeneidad de la movilidad de poblaciones, como la de los mexicano-guatemaltecos, presenta ese desafío. Tendemos a emplear criterios y clasificaciones fijos, 
pero situaciones como las migraciones continuadas, las migraciones de origen multicausal - por ejemplo, por violencia o razones económicas-, o los procesos de migración de "tránsito en espera" hacen que las actuales formulaciones, rígidas, resulten limitadas. ¿Cuál es la lectura, en términos generacionales, de la multimovilidad experimentada por esta comunidad? Vista desde el enfoque prolongado, la primera generación ha vivido la mayor gama de experiencias de movilidad, principalmente desde y hacia Guatemala y México y, menos, hacia Estados Unidos. De hecho, algunos informantes iniciaron sus experiencias de movilidad desde la década de 1960. Los individuos de la generación 1.5 -y 2 en algunos casos- que sí regresaron a Guatemala entre 1984 y 1999 quizás sean los protagonistas de la mayor movilidad entre México y Guatemala (ver cuadro ly casos ilustrativos), a la vez que fueron las generaciones pioneras de la emigración a tierras estadounidenses. Ciertamente, la segunda generación y sus descendientes son partícipes de las migraciones más dinámicas: el contra-retorno a México y la migración hacia Estados Unidos. Esta primera exploración también abrió una senda para atisbar temáticas pendientes de análisis, uno de los cuales, que llama poderosamente la atención, es el tema de "volver a empezar". Con cada movilidad, en cada reubicación, las personas tuvieron que rehacer su vida prácticamente de la nada para echar raíces nuevamente. De manera similar a lo afirmado por Kristin Stølen al referirse a los retornados, pero que yo extiendo a los mexicano-guatemaltecos de Utepe que se han movido muchas veces en un período de tiempo relativamente breve, todos ellos han sostenido una relación pragmática con la idea de los lugares que "territorializan" (2009: 98). Además, los procesos de arraigo, desarraigo o movilidades continuadas encierran un rico material sobre las ideas y formas de concebir la ciudadanía, la identidad y la pertenencia de estas poblaciones. Casos como el hijo de Lucas y Jacinta, de 23 años, que no obstante ser mexicano de nacimiento también se sentía plenamente guatemalteco, pueden brindar algunas respuestas al respecto.

\section{Notas}

${ }^{1}$ Este trabajo es resultado de la investigación realizada gracias al Programa UNAM-DGAPA-PAPITT IA400214-2. El autor agradece los valiosos comentarios de los revisores y de Suleikys Guerra Domínguez.

2 "Referencia primaria" es el lugar en el cual se anclan diversas clases de movilidad, sin necesariamente ser el lugar de origen primigenio de quienes se movilizan.

${ }^{3}$ Stephen Castles aboga por crear teorías de migración de medio alcance dentro de un paradigma de cambio social (Castles, 2010: 1578). Existen otras críticas al paradigma de la movilidad (Kalir, 2013).

${ }^{4}$ La situación de los desplazados del archipiélago de Chagos comparte similitudes con la experiencia de los exrefugiados guatemaltecos y sus descendientes (Jeffery, 2010: 1113).

${ }^{5}$ Arriola (2014) encontró casos de migrantes deportados a municipios de Campeche y de Tabasco.

${ }^{6}$ Estadísticas del Gobierno estadounidense muestran que en 2013 la cifra era de 88 042; el año más crítico fue 2009, cuando fueron devueltos a México 468699 migrantes (United States. Department of Homeland Security, 2014: 105, tabla 40).

${ }^{7}$ Según el último censo nacional (2010) la población del lugar era de 2251 personas (INEGI, 2010).

${ }^{8}$ Estos son: ascendencia por parentesco, generación igual a cohorte, generación a modo de trayectoria de vida, y generación como período histórico particular, definido subjetivamente (Loizos, 2007: 195). Este mismo autor plantea que hay otras formas de investigar grupos en diversos momentos sin recurrir al término generación (Loizos, 2007: 206-208).

9 En términos generales, "ladino" es sinónimo del término "mestizo", utilizado en México. Entre los ladinos se incluyó a una mujer de origen salvadoreño, Iris (entrevista 14). Ella llegó a temprana edad a Guatemala, vivió la experiencia de un proceso de colonización en El Petén e ingresó a México como refugiada.

10 Antes de 1985 el Ixcán abarcaba parte del territorio norte de los departamentos de Huehuetenango y El Quiché. En el año referido se creó el municipio 
homónimo. Para una descripción general e histórica de la zona (COINDE, 1993: 11-14).

${ }^{11}$ Los "no reconocidos" se dispersaron entre la población mexicana, especialmente en Chiapas (Salvadó, 1992).

12 Timotea vivió en un campamento ubicado en el municipio de Las Margaritas. En 1991 ese campamento se encontraba en la lista de aquellos reconocidos oficialmente por ACNUR (Austin, 1996: anexo 5).

${ }^{13}$ La migración femenina posiblemente fue más común de lo que se detectó en este trabajo; sólo una mujer, Maricela, salió a trabajar durante su adolescencia. En una comunidad retornada, Rachel Manson-Smith entrevistó a cincuenta mujeres, de las cuales quince afirmaron que habían trabajado, como cocineras y empleadas domésticas, fuera de las comunidades donde vivieron durante el refugio (Manson-Smith, 2002: 103).

${ }^{14}$ A diferencia de los primeros años, cuando subsistieron de la comida proporcionada por ACNUR y COMAR, hacia el final de la década de 1990 los refugiados ya habían establecido las bases de su autosuficiencia alimentaria en Campeche y Quintana Roo (Garaiz, 1999).

${ }^{15}$ Un reducido grupo también obtuvo asilo en Canadá; este flujo que ha sido poco estudiado.

${ }^{16}$ Uno de esos primeros destinos fue Indiantown, en Florida, en especial para los q'anjobal (Burns, 1993).

17 La situación en Victoria 20 de Enero resulta aleccionadora. Seis años después del retorno (1999), el lugar aún carecía de agua potable y puesto de salud; además, existía una fuerte división interna entre la gente (Rosseau et al., 2005).

${ }^{18}$ En este trabajo contamos con algunos elementos para comentar el caso de Entre Ríos, en el municipio de Sayaxché, El Petén. Los retornados que llegaron allá eran originarios, principalmente, de la Cooperativa San Juan Ixcán fundada en 1974 (Manson-Smith, 2002: 95). Aunque la cooperativa fue reestablecida estando en México porque los fundadores mantuvieron las bases de su organización (Manson-Smith, 2002: 95), no todos los miembros originales pudieron retornar a ella debido a que los terrenos fueron ocupados por gente llegada después de 1982. Solamente una fracción de los residentes originales, los que estuvieron en Chiapas, fue reubicada en parcelas que no estaban ocupadas. A Entre Ríos se llegaba, primero, tomando una lancha, y luego caminando; desde el área central de El Petén ese viaje tomaba cuatro horas (Everardo, entrevista 10). Con el retorno organizado, en mayo de 1996, 68 familias fueron llevadas a Entre Ríos, si bien la finca tenía la extensión suficiente para haber acogido a dieciséis familias más, según Everardo; en la versión de otro informante, Ramiro (entrevista 16), fueron cuarenta las familias originarias de San Juan Ixcán que llegaron allá. Manson-Smith (2002) reportó que 74 familias habitaban en la comunidad en 2001. Al inicio ACNUR les dio apoyo en especie -láminasy en dinero para reiniciar sus vidas. La gente cultivó maíz en terrenos cercanos al poblado, pero hizo poco o ningún uso de las parcelas que les asignaron —43 hectáreas a cada uno- porque estaban muy alejadas del poblado. También había potreros, pero la gente no contaba con dinero para su restauración o mantenimiento. Con el tiempo la cooperativa decayó por falta de buena administración y otros problemas. Mucha gente ha vendido sus tierras y ya sólo cuentan con el solar. Por lo menos veinte de los retornados regresaron a México, una parte de ellos a Campeche (notas, Everardo). El trabajo de Julie Stewart (2012) es otro ejemplo de un análisis comparativo de dos comunidades de retornados en dos momentos diferentes - 1998 y 2003-.

${ }^{19}$ Además de Manuela Camus, otros autores han analizado lo que significó el retorno y la movilidad ulterior de los retornados visto desde Guatemala (Hurtado, 2001; Falla, 2006).

${ }^{20}$ No se entrevistó a ninguna mujer que haya ido y regresado o haya sido deportada desde Estados Unidos; sólo hay registro indirecto de una mujer migrante: la hermana de Mateo.

${ }^{21}$ No se descarta la posibilidad de que este estudio adolezca de un subregistro, porque alguien que manifestó haber regresado voluntariamente en realidad puede haber ocultado que fue expulsado de Estados Unidos. 


\section{Referencias bibliográficas}

ACNUR (2009). "Refugee Protection and Mixed Migration: The 10-Point Plan in Action". S.l: ACNUR. Disponible en: http:/www.unhcr.org/cgi-bin/texis/vtx/home/opendocPDFViewer.html?docid=4a855cd52e\&query=Refug ee\%20protection\%20and\%20mixed\%20migration.

Armas, José (2009). "Os impactos socioeconómicos da emigración de retorno en Galicia. Estudo de caso no concello de Antas de Ulla (Lugo)". En Estudos Migratorios. Revista Galega de Análise das Migracións, vol. II, núm. 1, pp. 109-133.

Arriola, Luis (2014). "Return Migration from the United States to Rural Areas of Campeche and Tabasco". En Migraciones Internacionales, vol. 7, núm. 4, pp. 101-135.

Artimus, Millet (1974). "The Agricultural Colonization of the West Central Peten, Guatemala. A Case Study of Frontier Settlement by Cooperatives". Tesis de doctorado, Eugene, University of Oregon.

Austin, Steven (1996). "Into the Mouth of the Wolf': Guatemalan Refugees Prepare For Repatriation”. Tesis doctoral, Washington D.C., The American University.

AVANCSO (1990). Política institucional para el desplazado interno en Guatemala. Guatemala: AVANCSO. Cuadernos de Investigación, núm. 6.

AVANCSO (1992). ¿Dónde está el futuro? Procesos de reintegración en comunidades de retornados. Guatemala: AVANCSO. Cuadernos de Investigación, núm. 8.

Bhatt, Wasudha y Bryan R. Roberts (2012). “Forbidden Return': Return Migration in an Age of Restriction". En Journal of Immigrant and Refugee Studies, vol. 10, núm. 2, pp. 162-183.

Bivand, Marta y Rojan Ezzati (2015). “'Where are You From' or 'When did You Come'? Temporal Dimensions on Migrants' Reflections about Settlement and Return". En Ethnic and Racial Studies, vol. 38, núm. 7, pp. 1202-1217.

Binaisa, Naluwembe (2011). "Negotiating 'Belonging' to the Ancestral 'Homeland': Uganda Refugee Descendents 'Return'. En Mobilities, vol. 6, núm. 4, pp. 519-534.

Burns, Allan (1993). Maya in Exile. Guatemalans in Florida. Filadelfia: Temple University Press.

Camus, Manuela (2008). La sorpresita del norte. Migración internacional y comunidad en Huehuetenango. Guatemala: INCEDES/CEDFOG

Cassarino, Jean-Pierre (2004). "Theorising Return Migration: The Conceptual Approach to Return Migrants Revisited".
En International Journal on Multicultural Societies, vol. 6, núm. 2, pp. 253-279.

Castañeda, Alejandra (2012). "La violencia de la ley: la legislación migratoria y el proceso de deportación". En María D. París (coord.), Migrantes, desplazados, braceros y deportados: experiencias migratorias y prácticas políticas. Tijuana: COLEF/UNAM/UAM, pp. 297-331.

Castillo, Manuel A. (1999). "Causas del éxodo: procedencia y características étnicas de la población refugiada”. En Memoria, presencia de los refugiados guatemaltecos en México. México: COMAR/SEGOB/ACNUR, pp. 32-38.

Castles, Stephen (2010). "Understanding Global Migration: A Social Transformation Perspective". En Journal of Ethnic and Migration Studies, vol. 361, núm. 10, pp. 1565-1586.

CEH (Comisión para el Esclarecimiento Histórico) (1999) Informe de la Comisión para el Esclarecimiento Histórico. Guatemala: CEH.

Chimni, Bhupinder S. (2002). "Refugees, Return and Reconstruction of 'Post-Conflict' Societies: A Critical Perspective". En International Peacekeeping, vol. 9, núm. 2, pp. 163-180.

COINDE (1993). Colonización, desarraigo y condiciones de retorno. Guatemala: COINDE.

Collyer Michael y Hein de Haas (2012). "Developing Dynamic Categorisations of Transit Migration". En Population, Space and Place, vol. 18, núm. 4, pp. 468-481.

Cwerner, Saulo B. (2001). "The Times of Migration". En Journal of Ethnic and Migration Studies, vol. 27, núm. 1, pp. 7-36.

De Genova, Nicholas (2010). "The Deportation Regime. Sovereignty, Space and the Freedom of Movement". En Nicholas de Genova y Nathalie Peutz (eds.), The Deportation Regime. Sovereignty, Space and the Freedom of Movement. Durham y Londres: Duke University Press, pp. 33-65.

Debry, Joanna (2012). "The Burden of Deportation of Children in Mexican Immigrant Families". En Journal of Marriage and Family, vol. 74, núm. 4, pp. 829-845.

Durand, Jorge (2004). "Ensayo teórico sobre la emigración de retorno. El principio del rendimiento decreciente". En Cuadernos Geográficos, núm. 35, julio-diciembre, pp. 103-116.

Falla, Ricardo (2006). Juventud de una comunidad maya. Ixcán, Guatemala. Guatemala: AVANCSO.

Ferrás, Carlos (1999). "Desde Avión para Jalisco. Historia y perfil socioeconómico de la emigración gallega hacia 
México en la segunda mitad del siglo XX". En Semata, núm. 11, pp. 381-394.

Findlay, Allan, David McCollum, Rory Coulter y Vernon Gayle (2015). "New Mobilities Across the Life Course: a Framework for Analysing Demographically Linked Drivers of Migration”. En Population, Space and Place, vol. 21, núm. 4, pp. 309-402.

Garaiz, Esteban (1999). "Los derechos humanos y los refugiados guatemaltecos". En Memoria, presencia de los refugiados guatemaltecos en México. México: COMAR/SEGOB/ACNUR, pp. 118-122.

García, Máximo (1999). "Programa de apoyo a la repatriación voluntaria". En Memoria, presencia de los refugiados guatemaltecos en México. México: COMAR/SEGOB/ACNUR, pp. 146-149.

Gardner, Katy (2002). Age, Narrative and Migration: The Life Course and Life Histories of Bengali Elders in London. Oxford: Berg.

Gmelch, George (1980). "Return Migration”. En Annual Review of Anthropology, núm. 9, pp. 135-59

González, Oscar (1999). "Reubicación a Campeche y Quintana Roo: promoción de soluciones, 1984-1988”. En Memoria, presencia de los refugiados guatemaltecos en México. México: COMAR/SEGOB/ACNUR, pp. 72-75.

Hess, Sabine (2012). "De-naturalising Transit Migration.Theory and Methods of An Ethnographic Regime Analysis". En Population, Space and Place, vol. 18, núm. 4, pp. 428-440.

Hurtado, Laura (2001). "Factores determinantes de migraciones emergentes en comunidades de reasentados en Ixcán, 19972000". Tesis de maestría. Guatemala, Universidad del Valle de Guatemala.

INEGI (2010). Censo de Población y Vivienda 2010. Principales resultados por localidad (ITER). México: INEGI. Disponible en: http:/www3.inegi.org.mx/sistemas/mexicocifras/ExportaIndicadores.aspx?ag=04002\&nent=Campeche\&nmun= Campeche\&lang=es\&src $=487$ \& $r e c=0$.

Jasso, Guillermina (2003). "Migration, Human Development, and the Life Course". En Mortimer Jeylan T. y Shanahan Michael J. (eds), Handbook of the Life Course. Nueva York: Springler, pp. 331-367.

Jeffery, Laura (2010). "Forced Displacement, Onward Migration and Reformulations of 'Home' by Chagossians in Crawley, UK”. En Journal of Ethnic and Migration Studies, vol. 36, núm. 7, pp. 1099-2017.

Jeffery, Laura y Jude Murison (2011). "The Temporal, Social, Spatial, and Legal Dimensions of Return and Onward
Migration”. En Population, Space and Place, vol. 17, núm. 2, pp. 131-139.

Jonas, Susanne y Néstor Rodríguez (2015). Guatemala-U.S. Migration: Transforming Regions. Austin, Texas: The University of Texas Press.

Kalir, Barak (2013). "Moving Subjects, Stagnant Paradigms: Can the 'Mobilities Paradigm' Transcend Methodological Nationalism?" En Journal of Ethnic and Migration Studies, vol. 39, núm. 2, pp. 311-27.

Kauffer, Edith (2000). Refugiados de Guatemala en México. México: Instituto Nacional Indigenista.

Kertzer, David (1983). “Generation as a Sociological Problem”. En Annual Review of Sociology, núm. 9, pp. 125-149.

King, Russell (2012). "Geography and Migration Studies: Retrospect and Prospect". En Population, Space and Place, vol. 18, núm.2, pp. 134-153.

King, Russell y Anastasia Christou (2010). "Cultural Geographies of Counter-Diasporic Migration: Perspectives from the Study of Second-Generation 'Returnees' to Greece”. En Populations, Space and Place, vol. 16, núm. 2, pp. 103-119.

King, Russell y Anastasia Christou (2011). "Of CounterDiaspora and Reverse Transnationalism: Return Mobilities to and from the Ancestral Homeland". En Mobilities, vol. 6, núm. 4, pp. 451-466.

King, Russell, Mark Thomson, Tony Fielding y Tony Warnes (2006). "Time, Generations, and Gender in Migration and Settlement”. En Rhinus Penninx, Maria Berger y Karen Kraal (eds.), The Dynamics of International Migration and Settlement in Europe. A State of the Art. Amsterdam: IMISCOE Joint Studies, Amsterdam University Press, pp. 233-267.

Lerma, Enriqueta (en prensa). "Guatemalteco-mexicanoestadounidenses' en Chiapas: Familias con estatus ciudadano diferenciado y su multiterritorialidad". En Migraciones Internacionales.

Lietaert, Ine, Ilse Derluyn y Eric Broekaert (2014). "Returnees' Perspectives on Their Re-emigration Process". En International Migration, vol. 52, núm. 5, pp. 144-158.

Loizos, Peter (2007). '“Generations' in Forced Migration: Towards Greater Clarity". En Journal of Refugee Studies, vol. 20, núm. 2, pp. 193-209.

Manson-Smith, Rachel (2002). "Women's Roles in Refugee Resettlement: A Case Study from Entre Ríos, Guatemala”. 
Tesis de maestría, Faculty of Graduate Studies, Guelph, The University of Guelph.

Martin, Susan, Sanjula Weerashinge y Abbie Taylor (2014). Humanitarian Crises and Migration. Londres: Routledge.

Melville, Thomas y Marjorie Melville (1982). Tierra y poder en Guatemala. San José, Costa Rica: Editorial Universitaria Centroamericana.

Memoria, presencia de los refugiados guatemaltecos en México (1999). México: COMAR/SEGOB/ACNUR.

ODHAG (1998). Recuperación de la Memoria Histórica, "Guatemala, Nunca Más". Guatemala: ODHAG.

Omata, Naohiko (2013). "The Complexity of Refugees' Return Decision-Making in a Protracted Exile: Beyond the HomeComing Model and Durable Solution". En Journal of Ethnic and Migration Studies, vol. 39, núm. 8, pp. 1281-1297.

Ortiz, Luis (2011). "Refugiados guatemaltecos: lecciones y aprendizaje". En Katya Somohano y Pablo Yankelevich (coord.), El refugio en México. Entre la historia y los desafios contemporáneos. México: SEGOB, pp. 49-54.

Pérez, Luis (1999). "El asiento seguro en Chiapas". En Memoria, presencia de los refugiados guatemaltecos en México. México: COMAR/SEGOB/ACNUR, pp. 136-143.

Rosseau, Cécile, Elena de la Aldea, Musuk Viger Rojas y Patricia Foxen (2005). "After the NGO's departure: Changing memory strategies of young Mayan refugees who returned to Guatemala as a community". En Anthropology \& Medicine, vol. 12, núm. 1, pp. 1-19.

Sáenz, Erasmo (1999). "El Proceso de CIREFCA [Conferencia Internacional sobre Refugiados Centroamericanos] y los refugiados guatemaltecos en México". En Memoria, presencia de los refugiados guatemaltecos en México. México: COMAR/ SEGOB/ACNUR, pp. 124-134.

Salvadó, Luis R. (1992). “Chiapas: Los refugiados no reconocidos”. En G. Freyermuth y R. A. Hernández (comp.), Una década de refugio en México: los refugiados guatemaltecosy los derechos humanos. México: CIESAS, pp. 106-118.

Sheller, Mimi (2011). "Mobility". En sociopedia.isa. Disponible en: http://www.sagepub.net/isa/admin/viewPDF. aspx?\&art=Mobility.pdf.

Stewart, Julie (2012). "Help or Hindrance: How Transnational Ties Shape Community Mobilization in Post-war Guatemala". Tesis de Doctorado en Sociología, Nueva York, New York University.
Stølen, Kristi (2009). "Place and Identity among Guatemalan Returnees”. En Forum for Development Studies, vol. 36, núm. 1, pp. 79-103.

Urry, John (1999). Sociology beyond Societies: Mobilities for the Twenty-First Century. Londres: Routledge.

United States. Department of Homeland Security (2014). "2013 Yearbook of Immigration Statistics. Office of Immigration Statistics, Department of Homeland Security". Agosto. Disponible en: http://www.dhs.gov/sites/default/files/ publications/ois_yb_2013_0.pdf.

Vallejo, Ivette (2000). "Ixcán Configuraciones de una region multiétnica: identidad, relaciones étnicas y conflicto". Informe de consultoría, Pastoral Social-IBIS/Dinamarca y CIRMA. Guatemala, 73 p.

Van Hear, Nicholas (2009). "Managing Mobility for Human Development: the Growing Salience of Mixed Migration" (with Rebecca Brubaker and Thais Bessa). S.l.: UNDP Human Development. Research Paper 2009/20. Nueva York: UNDP. Disponible en: http://hdr.undp.org/en/ reports/global/hdr2009/papers/HDRP_2009_20.pdf.

Van Hear, Nicholas (2011). "Forcing the Issue: Migration Crises and the Uneasy Dialogue between Refugee Research and Policy”. En Journal of Refugee Studies, vol. 25, núm. 1, pp. 2-24

Wheatley, Christine (2011). "Push Back: U.S. Deportation Policy and the Reincorporation of Involuntary Return Migrants in Mexico". En The Latin Americanist, vol. 55, núm. 4, pp. 35-60.

Wilson, Dean (2015). "Marginalizing Migrants: Illegality, Racialization, and Vulnerability". En Erich Good (ed.). The Handbook of Deviance. Hoboken, Nueva Jersey: John Wiley and Sons, pp. 504-520.

Yarris, Kristin y Heide Castañeda (2015). "Discourses of Displacement and Deservingness: Interrogating Distinctions between 'Economic' and 'Forced' Migration'. [Special Issue] En International Migration, vol. 53, núm. 3, pp. 64-69.

Zetter, Roger (1999). "Reconceptualizing the Myth of Return: Continuity and Transition Amongst the Greek-Cypriot Refugees of 1974". En Journal of Refugee Studies, vol. 12, núm. 1, pp. 1-22.

Zetter, Roger (2007). "More Labels, Fewer Refugees: Remaking the Refugee Label in an Era of Globalization". En Journal of Refugee Studies, vol. 20, núm. 2, pp. 172-192. 


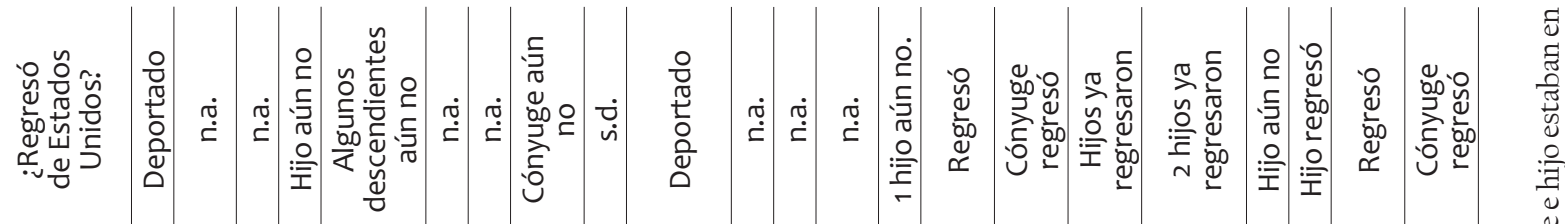

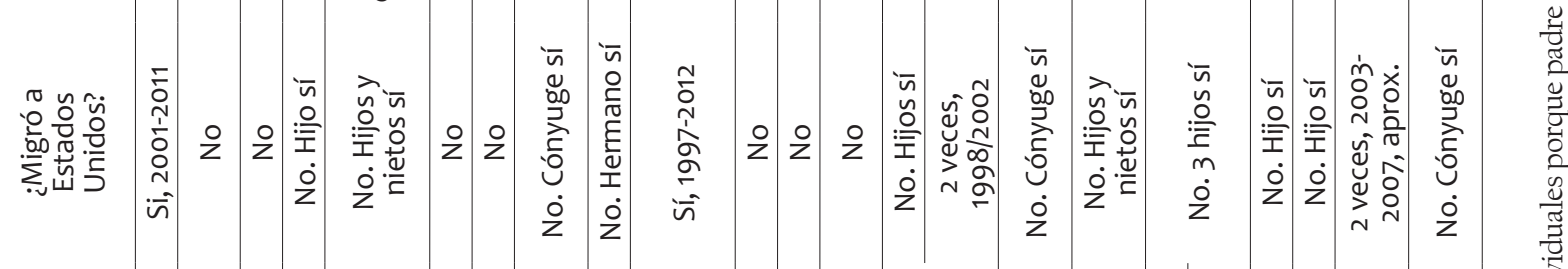

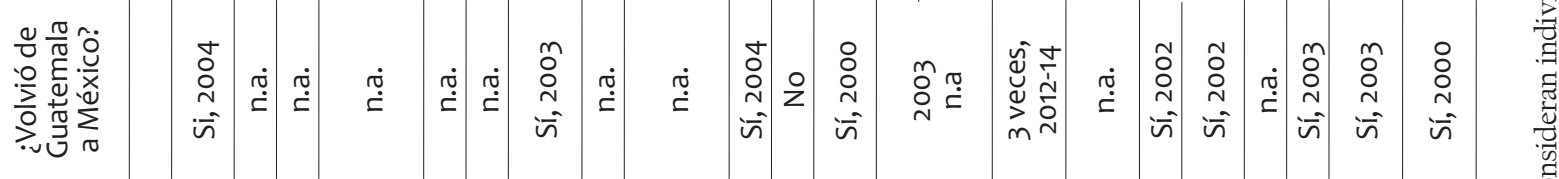

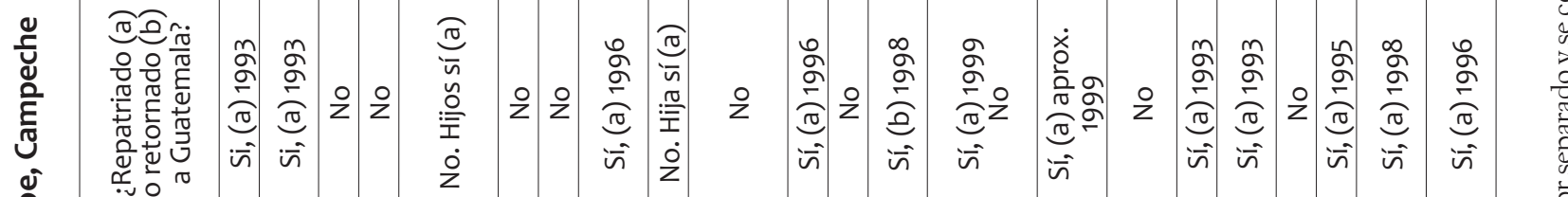

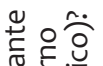
$\sum_{i=0}^{0.00}$

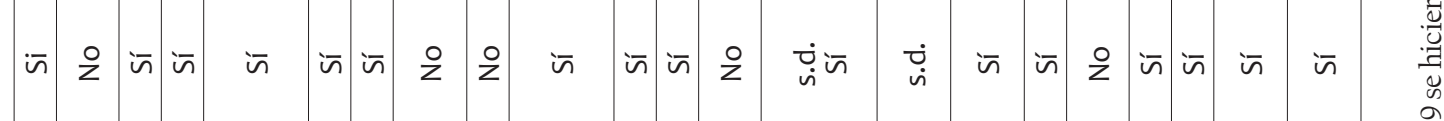

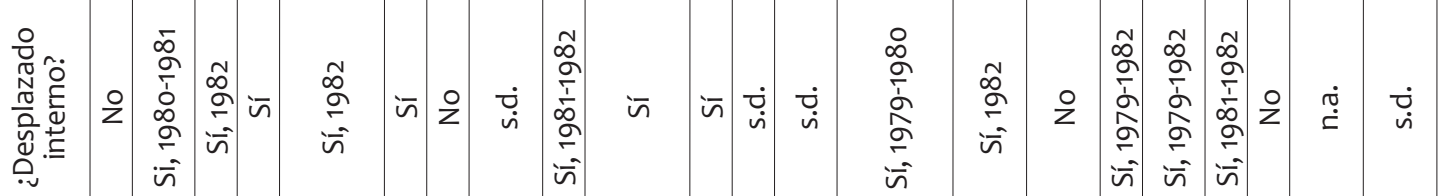

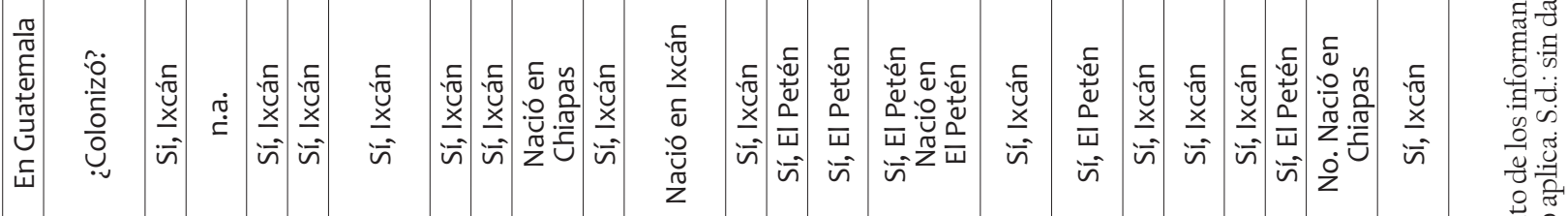

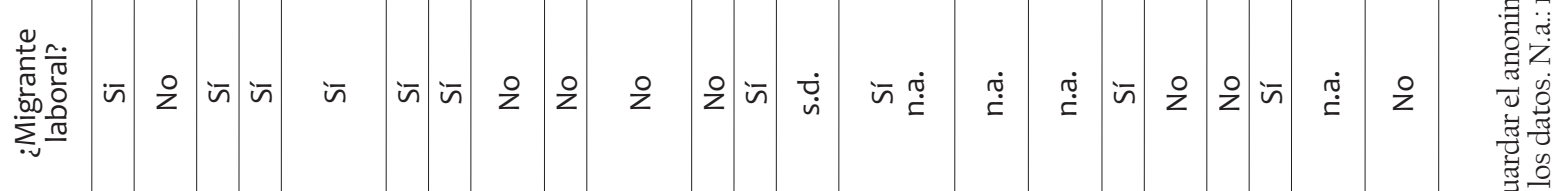

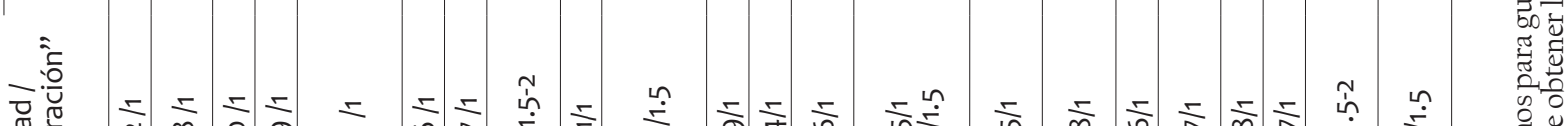

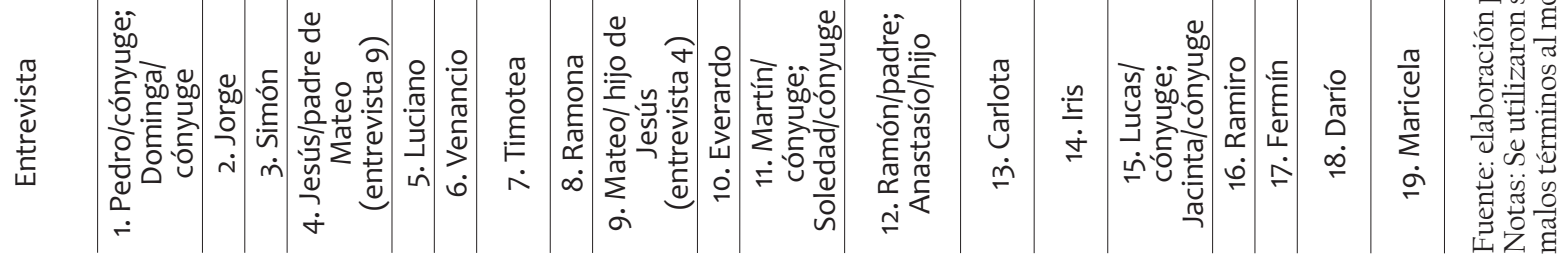

